\title{
Normalization and feasibility of speech understanding tests for Dutch speaking toddlers
}

\author{
Astrid van Wieringen *, Jan Wouters \\ Laboratory for Experimental Otorhinolaryngology, K. U. Leuven, Kapucijnenvoer 33, 3000 Leuven, Belgium
}

Received 25 November 2004; received in revised form 18 March 2005; accepted 23 March 2005

\begin{abstract}
As a result of newborn hearing screening programs, hearing impairment is often identified early in life and proper intervention (hearing aids, cochlear implant) will enable children to develop expressive and receptive skills as young as possible. The goals of this study are to obtain normative data on speech tests that are suitable for evaluation of young hearing-impaired Dutch speaking children in Flanders and the Netherlands and to determine the youngest age at which these tests are feasible. Normative data are obtained with 143 normal-hearing children with normal cognitive and language development for the Göttinger I (3-4 years) and Göttinger II (5-6 years). It is shown that one performance intensity curve can describe both tests. Moreover, a subsequent study with 35 normal-hearing children showed that the Göttinger I can also be administered to children with normal cognitive and language development younger than three years of age. In addition, the feasibility of two analytical tests was examined. These tests were designed to obtain information on the transmission of spectral and temporal speech cues by the hearing aid or cochlear implant in children as young as $2 \frac{1}{2}$ years of age.
\end{abstract}

(c) 2005 Elsevier B.V. All rights reserved.

Keywords: Normative data; Speech tests; Toddlers

\section{Introduction}

About three in 1000 babies are born with hearing impairment, making it one of the most common birth defects. Nowadays, newborn screening

\footnotetext{
${ }^{*}$ Corresponding author.

E-mail address: astrid.vanwieringen@uz.kuleuven.ac.be
} (A. van Wieringen). programmes enable early diagnosis and treatment. In Flanders, the Dutch speaking part of Belgium, the hearing of about $97 \%$ of all newborns is screened (van Kerschaver and Stappaert, 2002). Research has shown that early identification of hearing loss and early intervention result in significantly better speech understanding, significantly improved speech production and better attendance of mainstream schools (Yoshinaga-Itano et al., 
1998; Spencer et al., 1998, 2003; Svirsky et al., 2004). As it is acknowledged that the first few years of life are of critical importance for speech and language development, more and more hearing-impaired children either wear hearing aids or receive a cochlear implant at a very young age (if necessary, even younger than one year of age).

Early diagnosis and early intervention require speech tests that are suitable for very young children. Speech perception assessment in young, hearing-impaired children is a challenging task, as several internal and external factors must be considered that can influence test outcomes and affect the reliability and validity of paediatric speech perception procedures (Kirk et al., 1997). These factors include the child's vocabulary, language competency, chronological age, cognitive abilities, the designation of an appropriate response task, the utilization of reinforcement, and the extent of memory load inherent to the task. Like many other countries, Flanders and the Netherlands lack valid, sensitive, reliable, normalized, speech perception tests for young (pre-school) profoundly hearing-impaired children. Only a limited number of Dutch speech tests are available, among which the Göttinger I and Göttinger II (originally translated from German) and speech tests from the Dutch "Antwerpen-Nijmegen testbatterij" (Beijnon et al., 1992), the SAP-test (Crul, 1984), and the Flemish PAP-V test battery (van Wieringen et al., 1998). However, few (if any) of these tests are normalized or suitable for very young children. The goals of this study are to provide a normalized speech test for both Dutch-speaking and Flemish- speaking children (Huysmans, 1997), and to determine the youngest age at which this speech test is feasible (Goossens, 2004).

In addition to speech tests, alternative, analytical tests have been developed and evaluated by means of picture-pointing figures and an interactive, animated computer programme to determine the transmission of the most important spectral and temporal speech parameters with very young children in a reliable manner.

\section{Normalization of Göttinger I and Göttinger II}

In the late 1970s Der Göttinger Kindersprachverständnistest was translated and adapted for the Dutch language to the Göttinger I and Göttinger II tests (van Gompel and Vanhulle, 1979; Lambrechts, 1979). The Göttinger I (Table 1, 10 lists of 10 words) was developed for 3-4 year olds, while the Göttinger II (Table 2, 10 lists of 10 words) was meant for 5-6 year olds. The tests consist of monosyllabic words (nouns) that are presented in a four-alternative closed-response set in the same vowel context. All words in these tests are easily represented by a figure (Fig. 1). In order to be able to use the same tests in Flanders and the Netherlands some words were replaced (Huysmans, 1997). Dutch spoken in the Netherlands and in Flanders is essentially the same language, but it differs somewhat with respect to vocabulary and pronunciation. The normalization of the Göttinger lists was a joint cooperation between the Lab. Exp. ORL at the K.U.Leuven, A.Z.

Table 1

Table of Göttinger I for Dutch (Wouters et al., 1994a,b)

\begin{tabular}{llllllllllll}
\hline A & B & 1 & 2 & 3 & 4 & 5 & 6 & 7 & 8 & 9 \\
\hline ster & rook & maan & mand & ster & trui & beer & noot & boot & vlag & rook & vlees \\
maan & muis & vlieg & teen & rook & kam & vaas & vaas & peer & ster & mand & brief \\
vlees & kam & muis & vaas & vlag & teen & rook & trui & vlieg & rook & vaas & muis \\
soep & vlieg & rook & mes & trui & hoofd & maan & soep & mand & beer & brief & kam \\
noot & teen & kam & beer & maan & mes & boot & brief & ster & trui & vlees & vaas \\
mand & hoofd & ster & noot & vlieg & beer & mand & teen & maan & brief & soep & hoofd \\
peer & vaas & mand & trui & peer & vlag & vlees & vlag & hoofd & teen & mes & peer \\
trui & mes & vlees & soep & mes & noot & ster & rook & kam & maan & trui & mand \\
brief & beer & boot & vlag & boot & brief & muis & mes & trui & noot & peer & ster \\
boot & vlag & vaas & brief & teen & soep & kam & peer & beer & mes & vlag & noot \\
\hline
\end{tabular}


Table 2

Table of Göttinger II for Dutch (Wouters et al., 1994a,b)

\begin{tabular}{llllllllll}
\hline 1 & 2 & 3 & 4 & 5 & 6 & 7 & 8 & 9 & 10 \\
\hline fiets & kerk & bril & hond & been & gras & muis & mes & baard & brief \\
maan & naald & steen & bloem & schip & kind & koord & haan & zak & kaars \\
buik & stoel & weg & huis & bal & schoen & beer & plant & peer & fluit \\
schaar & lamp & boom & lip & kers & zon & strik & leeuw & dik & hand \\
poort & bos & trui & dak & mand & vlieg & plas & kin & melk & stok \\
kam & gang & bank & wieg & doos & eend & zwaan & ster & snoep & glas \\
rok & wiel & aap & teen & start & pruim & knie & bol & pot & noot \\
vlag & fruit & tong & kooi & mond & schaap & bord & truin & ruit & vis \\
fles & zee & berg & pet & kaas & bel & hemd & brood & bier & pen \\
kip & wind & drie & trap & vuist & poot & bak & dier & arm & vlees \\
\hline
\end{tabular}
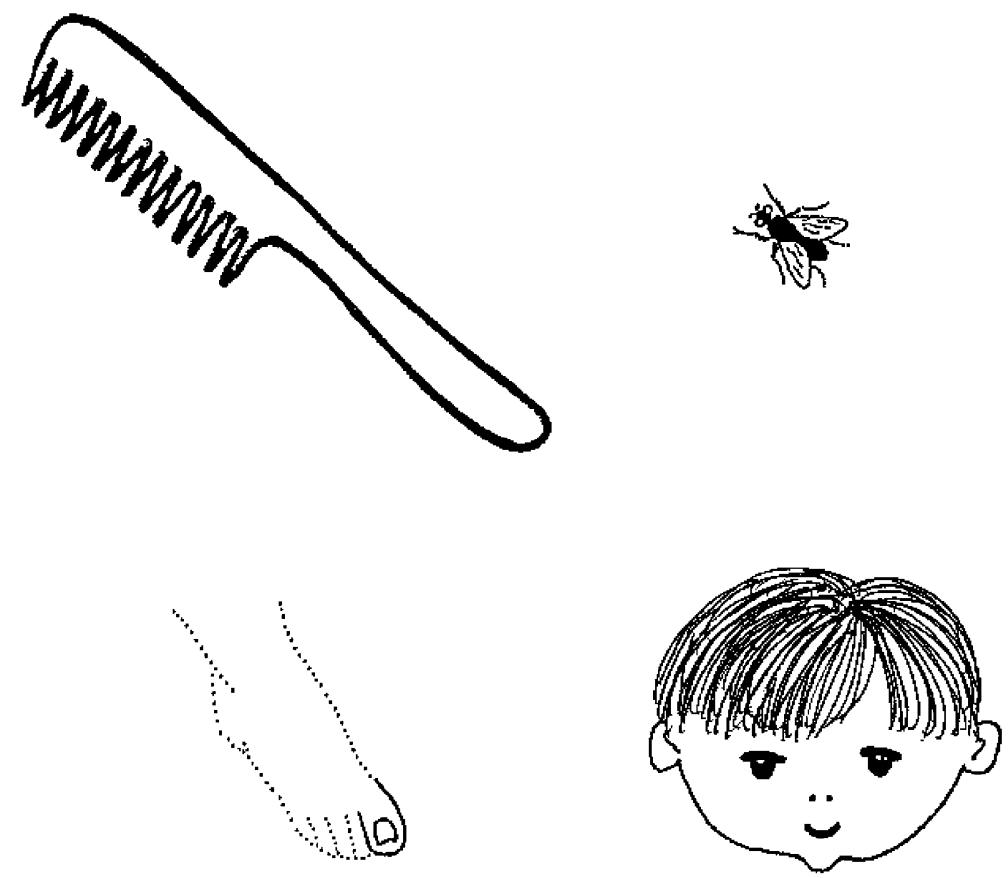

Fig. 1. Response format in the Göttinger tests.

Sint-Jan in Brugge, de Katholieke Vlaamse Hogeschool Antwerpen (now Lessius Hogeschool), and the Rehabilitation Center of Sint-Lievenspoort in Gent.

By testing 143 children, a reference speech intelligibility curve is obtained for normal-hearing children aged between three and six years. In this study it is examined whether the Göttinger I and Göttinger II yield the same performance intensity curves and whether the Göttinger I test can be administered to children younger than three years of age.

\subsection{Recordings}

Recordings were made in the anechoic room of the Acoustics and Thermal Physics department (K.U. Leuven). One female speaker produced all the utterances using a B\&K 4165 microphone. Recordings were routed through a B\&K 2639 
pre-amplifier and a B\&K 2610 amplifier to a digital studio DAT-recorder TASCAM DA-30, using a sampling rate of $44,100 \mathrm{~Hz}$ and a $16-\mathrm{bit} \mathrm{A} / \mathrm{D}$ converter. All speech tokens were equated with respect to the RMS values. The speech materials of the Göttinger I and Göttinger II were recorded, together with the NVA lists for older children and three lists for adults, on the CD "Vlaamse opname van woordenlijsten voor spraakaudiometrie" (Bosman et al., 1995; Wouters et al., 1994a,b).

\subsection{Subjects}

A total of 143 normal-hearing children participated in this study. They were tested in different parts of Flanders: Leuven (48), Brugge (40), Antwerpen (41) and Gent (14). Normal hearing of the youngest children (Göttinger I) was assessed by means of an ENT check-up, while that of the older ones (Göttinger II) was assessed on the basis of a tympanogram and stapedius reflex measurement. In total, 67 children, 40 boys and 27 girls, ranging from $3 ; 0$ to $4 ; 11$ years, participated in the evaluation of Göttinger I (average age was $4 ; 3$ years), while 76 children, 32 boys and 44 girls, ranging from $5 ; 1$ to $6 ; 11$ years participated in the Göttinger II test (the average age was 6;0 years).

\subsection{Procedure and scoring}

The children were tested in a quiet room. All stimuli were routed from a CD player via a clinical audiometer (from Madsen or Interacoustics, different from center to center) to a headphone (TDH39). With the Göttinger I, the practice lists were first presented bilaterally at $60 \mathrm{~dB}$ SPL. There were no practice lists for the Göttinger II. In both tests, six of the 10 lists were administered to the children. The order of the six different test lists varied from child to child. In Leuven, Brugge and Gent the starting level was $50 \mathrm{~dB}$ SPL for both Göttinger I and Göttinger II. In Antwerp the starting level was $40 \mathrm{~dB}$ SPL in both tests. For each of the following six lists the level was decreased by $5 \mathrm{~dB}$ SPL, so that the lowest level at which a list was presented was $25 \mathrm{~dB}$ SPL in Leuven, Brugge and Gent and $15 \mathrm{~dB}$ SPL in Antwerp. The child responded to the word by pointing at one of four figures (the test word and three distractors). The response set changed for each token on the list. The three distractors had the same vowel as the test word, but different consonants (Fig. 1). One or two of the distractors were part of the word material, the others did not occur in the test material. Prior to the present study all the figures were evaluated by 8 adults and 27 children in different phases of active and passive, productive and receptive recognition. Children were also asked to draw figures of some of the words. Several ambiguous figures were modified (Huysmans, 1997). Six figures were changed for the Göttinger I test, 27 figures were changed for the Göttinger II test. During testing the children were also allowed to say the word out aloud. As every list consists of 10 words, the final word score is $n \times 10 \%$ per list (" $n$ " being the number of correct responses).

\subsection{Results}

Fig. 2 illustrates the performance intensity curves of the Göttinger I and Göttinger II, averaged over the four study centers. The speech reception threshold (SRT), which is defined as the intensity at which $50 \%$ of the words is understood correctly, either by repeating them or by pointing to pictures, was determined by fitting each of the 143 performance intensity curves by means of nonlinear regression analysis (SPSS 12.0, 2004). A multivariate ANOVA showed that the two Göttinger tests did not differ significantly with regard to the fitted SRT $[F=(1,127)=2.0, p=0.16]$ or

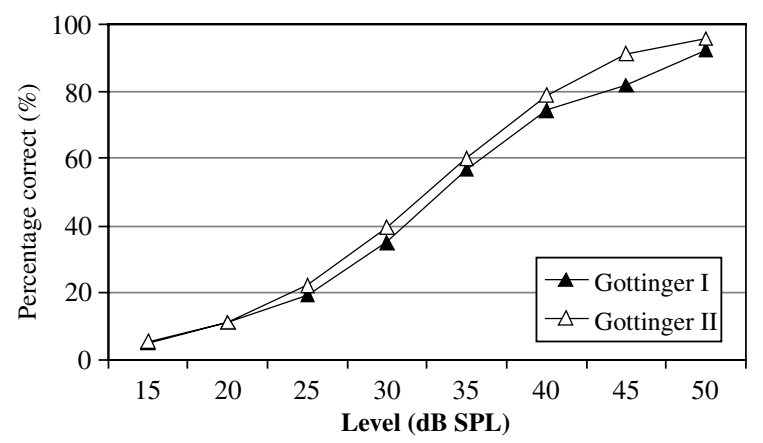

Fig. 2. Performance intensity curves of the Göttinger I and Göttinger II. 
fitted slope $[F=(1,127)=0.1, p=0.77]$. Similarly, no statistical significances were found with regard to the gender of the subject, neither for the fitted SRT $[F=(1,127)=0.14, p=0.71]$ nor for the fitted slope $[F=(1,127)=0.03, p=0.87]$. The fitted SRT was just statistically significant when comparing the data of the four different testing centers $[F=(3,127)=2.9, p=0.04]$. The fitted slopes were not statistically significantly different for the different testing centers $[F=(3,127)=1.2$, $p=0.30]$. Subsequent pairwise comparisons showed that only the fitted SRT's of Leuven and Brugge differed significantly from each other (Brugge about $2.9 \mathrm{~dB}$ lower SRT values), possibly because the children tested in Brugge were, on average, eight months older $(76 \mathrm{~m})$ than the children tested in Leuven $(68 \mathrm{~m})$. Fig. 2 also illustrates the slight difference between the performance intensity curves of the Göttinger I and Göttinger II. Despite this difference in performance the data of Göttinger I and Göttinger II compare well. Therefore, one performance intensity curve can represent the normative data of 3-6 year olds (if the Göttinger I is used for the 3-4 year olds and the Göttinger II for the 5-6 year olds). The average performance intensity curve, based on 143 children, is given in Fig. 3. The percentage correct word scores are also listed in Table 3, together with the standard deviations. Based on the individual fitted data, the average SRT of 143 children is 32.9 dB SPL (SD 4.4) and the average fitted slope is $5.3 \% / \mathrm{dB}$ ( $\mathrm{SD} 3.4$ ). After removing four slope values that were larger than twice the standard deviation due to inappropriate fits on deviant performance intensity curves, the more correct resulting average SRT and slope based on 139 children are $32.8 \mathrm{~dB}$ SPL (SD 4.4) and 4.9\%/dB (SD 1.8), respectively. The average slope compares well with those of the Dutch monosyllabic NVA list (4.8\%/ $\mathrm{dB})$ and the Brugse test lists $(4.5 \% / \mathrm{dB})$ (Wouters

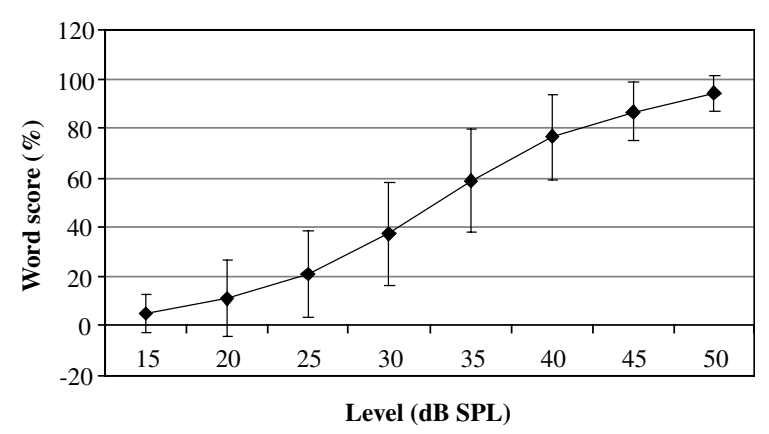

Fig. 3. Normal curve of Göttinger I and Göttinger II.

et al., 1994a,b). The differences between the SRT's of the different Dutch tests are larger, presumably because scoring criteria are often more stringent in adult tests. In the children's SAP test (Crul, 1984) the SRT corresponded to $38 \mathrm{~dB}$ SPL, while the SRT's of the adult Dutch NVA lists in quiet (open-set) and the Brugse list in quiet (open-set) corresponded to $19.0 \mathrm{~dB}$ SPL and $20.4 \mathrm{~dB}$ SPL, respectively (Wouters et al., 1994a,b). Note that the results of the monosyllabic adult tests are based on a phoneme score, while those of the children's test are based on word scores. In the NVA adult lists the SRT's based on word scores are about $5 \mathrm{~dB}$ higher than those based on phoneme scores.

\subsection{Conclusion}

One normalized curve has been obtained for Göttinger I and Göttinger II. However, despite normative data for 3-6 year olds, early diagnosis and early intervention require valid tests that can be administered at an even younger age. With this in mind it was subsequently examined whether the Göttinger I can be administered to children younger than three years of age.

Table 3

Percentage correct word scores, averaged over 143 children (data of Göttinger I and Göttinger II), together with the standard deviations (SD)

\begin{tabular}{|c|c|c|c|c|c|c|c|c|}
\hline & $15 \mathrm{~dB}$ & $20 \mathrm{~dB}$ & $25 \mathrm{~dB}$ & $30 \mathrm{~dB}$ & $35 \mathrm{~dB}$ & $40 \mathrm{~dB}$ & $45 \mathrm{~dB}$ & $50 \mathrm{~dB}$ \\
\hline Average & 5.1 & 11.2 & 21.9 & 38.1 & 57.7 & 76.5 & 87.0 & 93.1 \\
\hline SD & 7.5 & 14.7 & 17.1 & 20.2 & 21.5 & 17.2 & 12.7 & 9.3 \\
\hline
\end{tabular}




\section{Feasibility of the Göttinger I below three years of age}

\subsection{Subjects}

Although the Göttinger I test was developed for speech identification assessment in children 3-4 years of age, its feasibility was also determined for younger children. Thirty-five normal-hearing children with normal cognitive and language development, 17 girls and 18 boys between 2;0 and $2 ; 8$ years participated in this study. None of the children appeared to have language problems. The children were tested in a quiet room at home, in a day-care center or at kindergarten. First, the two practice lists of the 20 words used in Göttinger I were presented to determine whether the words were known by the child. Subsequently, the 10 lists of 10 monosyllable words of the Göttinger I were routed from a $\mathrm{CD}$ player to a loudspeaker that was positioned at $1 \mathrm{~m}$ from the child. The 100 stimuli were presented once at approximately $65 \mathrm{~dB}$ SPL. Usually two testing sessions were necessary to complete the 10 lists. Small rewards were given to motivate the children to complete the test.

\subsection{Results}

Twenty-eight of the 35 children were capable of performing the Göttinger I test. Of the seven others no score, however low, could be determined (missing values). Non-performance was due to shyness and lack of concentration or lack of vocabulary. A Kruskal-Wallis test (SPSS 12.0, 2004) showed that the data of children younger than $2 \frac{1}{2}$ years of age differed significantly from those of $2 \frac{1}{2}$ years of age and older $(p<0.004)$. Nevertheless, of the 14 children aged 24-28 months, eight of them were able to do the Göttinger I test and six of these eight did all 10 lists. One child obtained a score of $98 \%$ and six children obtained $80 \%$ or higher within 1 or 2 test sessions (Goossens, 2004). Some children performed well during the first testing session and poorly during the second testing session. The experimenter was able to administer all 10 lists of the Göttinger I to 17 of the 21 "older" children, while only 4-6 of the 10 lists were feasible with three of the four other chil-

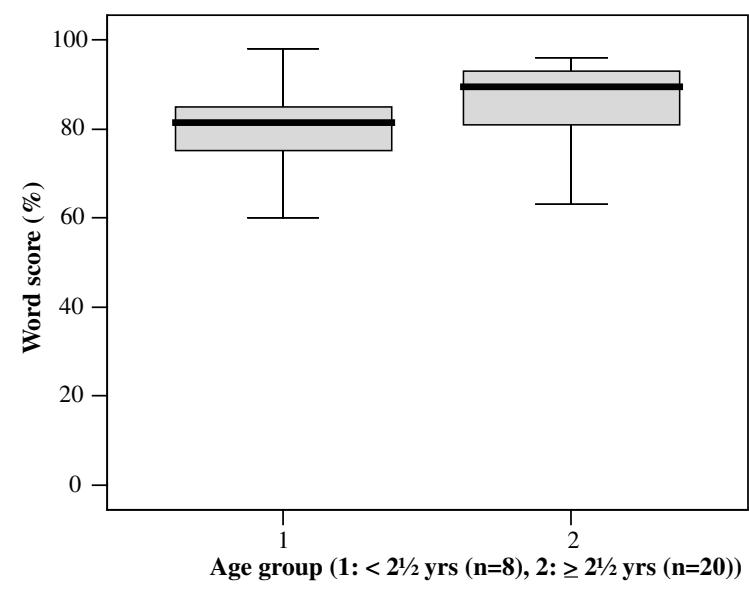

Fig. 4. Data of the Göttinger I test, presented at $65 \mathrm{~dB}$ SPL, for children younger than $2 \frac{1}{2}$ years of age (1) and children $2 \frac{1}{2}$ years of age and older (2).

dren. The fourth child could not be tested due to shyness. Many of the "older" children responded by pointing to the figures. However, nearly all the children younger than $2 \frac{1}{2}$ years of age responded by repeating the presented word. These two response types never yielded conflicting information. There was no significant effect of gender nor of testing place (home, day-care center or kindergarten, Mann-Whitney, $p>0.05)$.

Fig. 4 illustrates performance (percentage correct word score) for 8 children younger than $2 \frac{1}{2}$ years of age $\left(<2 \frac{1}{2}\right.$ years $)$ and 20 children of $2 \frac{1}{2}$ years and older ( $\geqslant 2 \frac{1}{2}$ years). The median of the younger age group was $81.5 \%(n=8$, six missing values), that of the older group was $89.5 \%$ ( $n=20$, one missing value).

\subsection{Conclusion}

Although the Göttinger I was developed for 34 year old toddlers, an additional study with 35 children aged between $2 \frac{1}{2}$ and 3;0 years showed that the test is feasible in normal-hearing children with normal cognitive and language development as young as $2 \frac{1}{2}$ years of age. Future studies will show at what age the Göttinger I is feasible in hearing-impaired children, who often have a different language competency compared to their normal-hearing peers. 
One way of by-passing a possible lack of language competency in young, hearing-impaired children is by administering analytical tests. Analytical tests (vowel and consonant recognition) enable us to determine the information transmission of important spectral and temporal cues with a hearing aid or cochlear implant (e.g. Dorman et al., 1990; Tyler and Moore, 1992; van Wieringen and Wouters, 1999). Data can be used to optimize the tuning or fitting of the hearing-aid or cochlear implant and can also guide rehabilitation (van Wieringen and Wouters, 2000). Evidently, preschool children cannot read or identify phonemes from a set of response alternatives. Therefore, the feasibility of an onomatopoeia test and an animated phoneme test with normal-hearing children will be discussed in the next section.

\section{Analytical tests in young pre-school children}

In an effort to characterize and quantify the development of auditory processing skills in preschool and school-aged children, an auditory test battery was developed in Belgium, in joint cooperation by the Lab. Exp. ORL (K.U.Leuven), the St Augustinus Hospital (Antwerp) and Philips Hearing Implants (later to be taken over by Cochlear Ltd). The Pediatric Auditory Performance Test for Flanders (PAP-V) was developed for the evaluation of profoundly hearing-impaired young Dutch speaking children between two and three years of age (van Wieringen et al., 1998). The test battery consists of 10 different (speech) perception tests, recorded on $\mathrm{CD}$, assessing performance on detection, discrimination and identification of suprasegmental and segmental speech perception aspects. Special attention was given to analytical tests, providing information about the child's speech feature discrimination abilities.

Several different tests of the PAP-V (detection, discrimination and identification of phonemes and words) were administered to groups of normalhearing children between two and seven years of age (a total of approximately 70), in order to determine reliability, test difficulty, and feasibility of the test procedures (Chanet, 1998; Gommers, 1998; Plasmans, 1999; Lemkens, 2000; van Hal, 2000).
In general, results indicate that children younger than three years are unable to fulfil the discrimination task due to cognitive aspects. Identification tests were always easier than (same-different) discrimination ones at all ages, although identification of environmental sounds was relatively difficult. Furthermore, some results were strongly influenced by the known vocabulary of the tested children. As analytical tests do not call on semantical knowledge, word familiarity does not have to be taken into account. An additional advantage of analytical tests is that results can be compared across languages. In adults, phoneme tests are administered in a closed-set identification tasks, resulting in stimulus-response confusion matrices that yield a wealth of information on the pattern of confusions of the subject (van Wieringen and Wouters, 1999). Results of the LAST (Leuven Analytical Speech Test) can be used to adjust the hearing aid or cochlear implant or to guide the rehabilitation programme. However, as the "adult" test procedure is not feasible with pre-school children, alternative ways of administering the test have been developed and evaluated with young normalhearing children with normal cognitive and language development. Two of these will be discussed. The first phoneme test consists of onomatopoeia: the child points to a figure that imitates the vowel or consonant. The second phoneme test concerns identification or discrimination of phonemes by means of an animated test using the computer programme APEX (Laneau et al., 2005). Once again, the goal of the study was to determine the youngest age at which this test is feasible.

\subsection{Onomatopoeia test}

The onomatopoeia test consists of three combinations of sounds (vowels or consonants) presented in a 3-AFC format. The sounds of the three combinations, /a-i-u/, /m-r-v/ and /f-s-sh/ are illustrated by figures (see Fig. 5). The stimulus sets were chosen to determine robust spectral and temporal properties of cardinal vowels and different manners of articulation. They were originally developed by "het Koninklijk Instituut voor Doven en Spraakgestoorden", the Royal Institute 

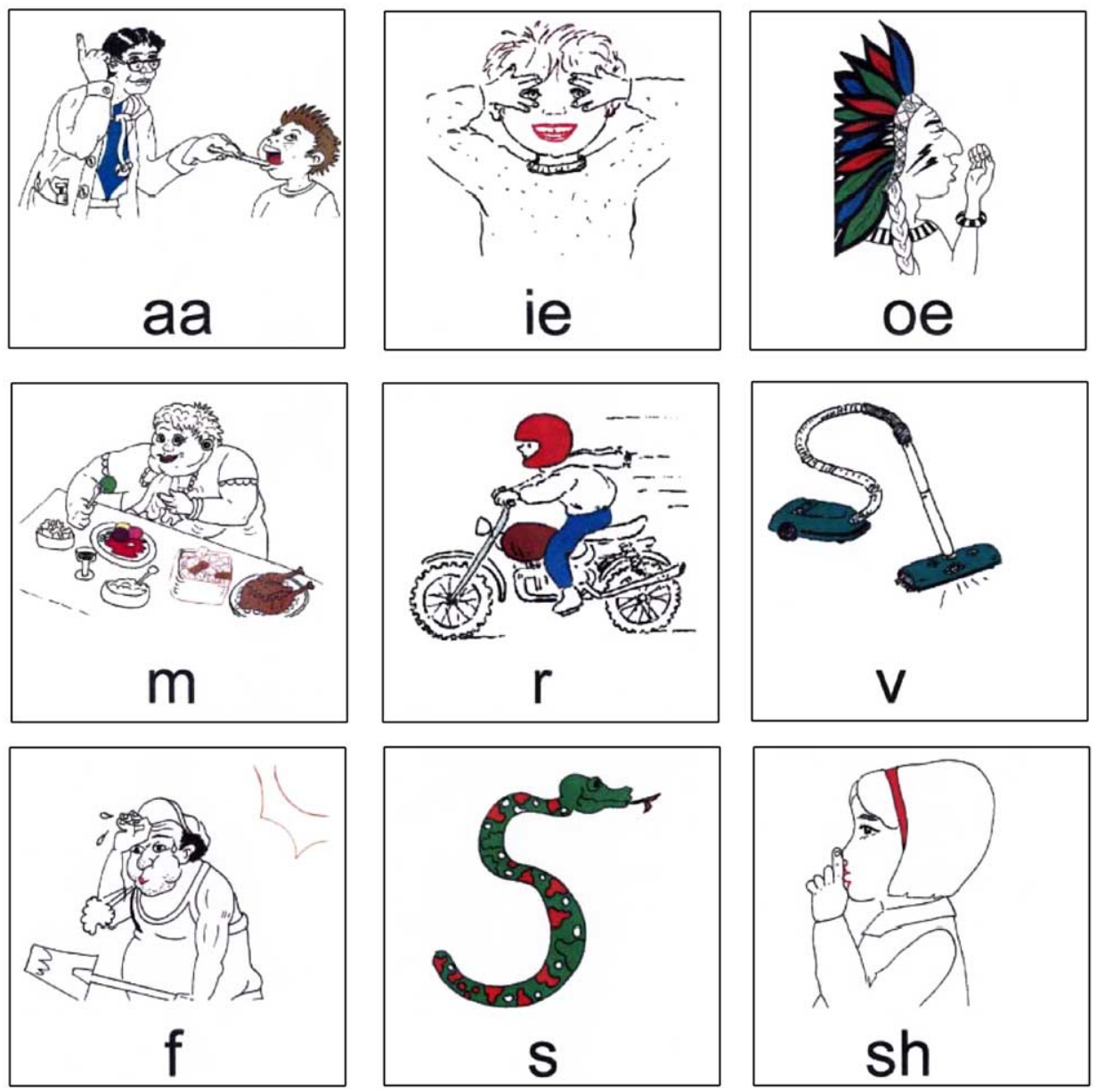

Fig. 5. Figure of three 3-AFC stimulus combinations in the onomatopoeia test.

for the Deaf in Hasselt, Belgium, and included in the PAP-V with new figures and different combinations of stimulus presentation (van Wieringen et al., 1998).

\subsection{LAST-pak}

The Leuven Analytical Speech Test (LAST) has been modified for toddlers ("peuters and kleuters" in Dutch, hence -pak) by presenting the phonemes in an animated and automated way. This is done by means of APEX (Application for PsychoElectrical eXperiments), a user-friendly and versatile research platform for use in auditory experiments
(Laneau et al., 2005). APEX takes care of automatic stimulus presentation and collection of the subjects' responses. The graphical user interface can be set up in a relatively sober mode for testing adults or in a highly animated mode for testing children. During tests with multiple-sound-interval trials, every interval is visually represented on the screen by a digit or character (adults) or a funny figure (monkeys, dinosaurs, snakes, or cars, see Fig. 6). The figures are animated synchronously with the presentation of the corresponding sound interval. The experimenter can have manual control over the initiation of consecutive trials and as such is able to initiate a trial only when the child 


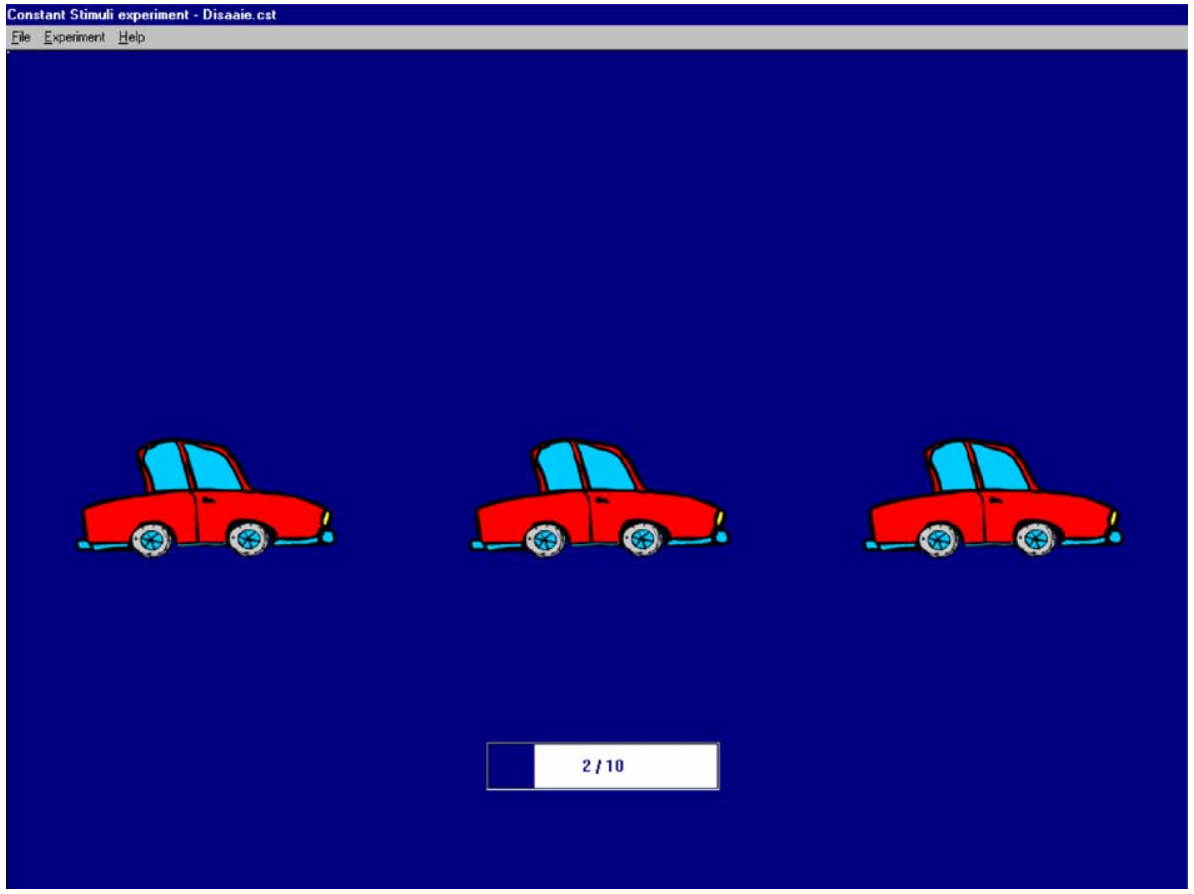

Fig. 6. Illustration of LAST-pak, phoneme identification by means of an animated and automated procedure APEX.

is attentive and looking at the monitor. The child's task is to choose, by pointing to the (touch) screen, which of the characters corresponds to the target sound. The child can be given an unlimited time in which to respond. Immediately after the child's response, visual feedback is given in the form of an animated cartoon. A correct response is reinforced with a special movement of the selected character. In case of an incorrect response, feedback (presented through animation of the misidentified character) is much more modest. During the sequence of trials constituting a single run, APEX can also provide a more global reinforcement by adding smiley faces to a rising ladder structure for every correct response. If the response is incorrect, a smiley is removed from the ladder structure. At the end of the run, the number of smiley faces may be evaluated and the child could be rewarded proportionally. The ladder structure with the smileys is continuously presented to the subject at the right of the computer screen. To round off the experiment and as a final reward for the child's achievement, an animated movie can be shown.
The movies are optional and can be skipped for children that require less conditioning. Also the reinforcement can be adjusted by leaving out feedback or omitting the ladder structure with the smileys.

At present, APEX contains animated cartoons, that have been used for gap-in-noise detection, frequency modulation detection and tone-in-noise detection experiments with normal-hearing children (Boets et al., submitted for publication; Vanrie, 2004). In the present study four different combinations of phonemes were administered: /i-a/, /u-a/ (vowel formant structure), /f-m/ (manner of articulation), and /s-z/ (voicing). The stimulus presentations were presented in a 2-AFC format (same-different) and a 3I2AFC format. In the latter format one of the speech sounds was presented twice in random order.

\subsection{Stimulus presentation and subjects}

For both phoneme tests the vowels and consonants were selected from the CD's of the PAP-V 
test battery. The wav-files were routed from the portable PC to a loudspeaker (presentation level approximately $65 \mathrm{~dB} \mathrm{SPL}$ ). In the onomatopoeia test each of the three stimulus combinations was presented 12 times (chance level $=33 \%$, significance level at $p<0.05=56 \%$ ). Prior to testing four practice items were presented. The child was informed that the car (or monkey) was going to make a sound. With the LAST-pak each of the four stimulus combinations was presented 10 times. Different tasks were considered, such as picking the odd one out, repeating the sounds and pointing to a sound. The onomatopoeia test conditions were evaluated with the same 35 normal-hearing children between $2 ; 0$ and 2;8 years who participated in the feasibility study of the Göttinger I (Section $3)$. The animated phoneme test was evaluated with seven normal-hearing children with normal cognitive and language development $(2 ; 1,2 ; 4,2 ; 5 ; 2 ; 6$; $2 ; 8,2 ; 10$, and $3 ; 2$ years of age).

\subsection{Results}

\subsubsection{Onomatopoeia}

Results differed for the three different combinations of sounds. In the /a-i-u/, /m-r-v/ and /f-s-sh/ no score was obtained for 7, 10 and 12 children (out of 35), respectively (missing values). Of the remaining children, 23 (out of $28 / \mathrm{a}-\mathrm{i}-\mathrm{u} /$ )), 19 (out of $25 / \mathrm{m}-\mathrm{r}-\mathrm{v} /$ ), and 15 (out of $23 / \mathrm{f}-\mathrm{s}-\mathrm{sh} /$ ) scored significantly above chance level. The same seven children who were unable to do the Göttinger I were unable to associate the speech sounds with the figures of the onomatopoeia test. In addition, several other young children found the onomatopoeia test much more difficult than the word identification test. This is partly attributable to the difficulty of illustrating a phoneme. For instance, the representation of the /a/ (a doctor looking into a child's throat) is easier to imagine for a $2 \frac{1}{2}$ year old than the representation of an /f/ (a person puffing, see Fig. 5). In addition, the presentation of the three cardinal vowels /a-i-u/ is spectrally more distinctive than the presentation of three fricatives that only differ in place of articulation.

Fig. 7 illustrates the results of the three different stimulus combinations in the onomatopoeia test. Once again, the data were divided into two age

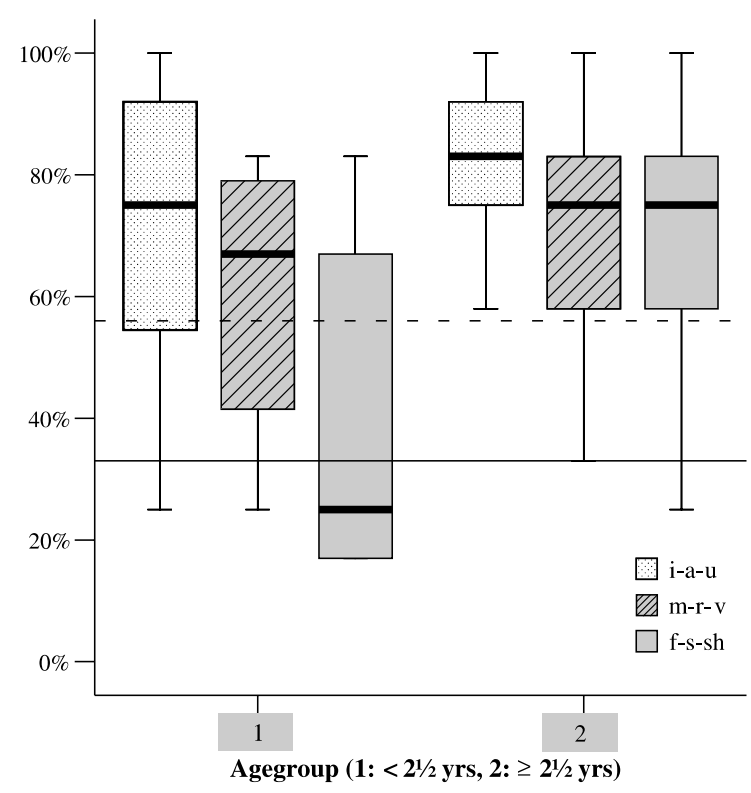

Fig. 7. Percentage of correctly identified onomatopoeia, presented at $65 \mathrm{~dB}$ SPL, for children younger than $2 \frac{1}{2}$ years of age (1) and for children aged $2 \frac{1}{2}$ years of age and older (2). The solid line illustrates chance level $(33 \%)$, the dotted line illustrates the significance level at $p<0.05$.

groups: the 14 children younger than $2 \frac{1}{2}$ years (1) and the 21 children of $2 \frac{1}{2}$ years and older (2). Kruskal-Wallis statistics on the data of the two age groups showed that the scores of the younger children differed significantly from those of the older children $(p<0.016$ for $/ \mathrm{i}-\mathrm{a}-\mathrm{u} /, p<0.012$ for $/ \mathrm{m}-\mathrm{r}-\mathrm{v} /$ and $p<0.002$ for $/ \mathrm{f}-\mathrm{s}-\mathrm{sh} /)$. In the younger age group the median scores were $75 \%(n=8$, six missing values), $67 \%$ ( $n=7$, seven missing values), and $25 \%(n=6$, eight missing values) for $/ \mathrm{i}-\mathrm{a}-\mathrm{u} /$, /m-r-v/ and /f-s-sh/ respectively. Of the children who could do the test, 2 (of 8), 3 (of 7) and 4 (of 6) scored below significance level $(56 \%)$ in $/ \mathrm{i}-\mathrm{a}-\mathrm{u} /$, $/ \mathrm{m}-\mathrm{r}-\mathrm{v} / \mathrm{and} / \mathrm{f}-\mathrm{s}-\mathrm{sh} /$, respectively. From $2 \frac{1}{2}$ years onwards children appear more capable of associating the speech sound with a figure. The median scores were $83 \%$ ( $n=20$, one missing value), $75 \%(n=18$, three missing values), and $75 \%(n=17$, four missing values) for $/ \mathrm{i}-\mathrm{a}-\mathrm{u} / \mathrm{/} / \mathrm{m}-\mathrm{r}-\mathrm{v} / \mathrm{and} / \mathrm{f}-\mathrm{s}-\mathrm{sh} / \mathrm{respec}-$ tively. Of those children who could do the test, 3 (of 20), 2 (of 18) and 4 (of 17) scored below significance level for /i-a-u/, /m-r-v/ and /f-s-sh/, respectively. 


\subsection{2. $L A S T$-pak}

First results of this analytical test with seven children were promising. All children enjoyed watching the intro- and outro-movies and the monkeys or cars on the screen, although the younger ones $\left(<2 \frac{1}{2}\right.$ years) became bored after 4 or 5 trials. Moreover, children younger than $2 \frac{1}{2}$ years of age have difficulty understanding the task(s). Most of the children were unable to point at "the odd one out" in, for instance, /i-i-a/, and all the children under three years of age made mistakes when asked to repeat the presented sequence of sounds, especially if the sounds were presented in a 3I2AFC format. Evidently, fewer mistakes were made when presented in a 2 -AFC format (samedifferent). However, the four children of $2 \frac{1}{2}$ years and older reliably pointed to the correct speech sound when asked to indicate, for instance, the /i/ in /a-a-i/. This was true for all four combinations of speech sounds.

\subsection{Conclusion}

Analytical tests are not meant to represent the child's performance in natural situations but to determine which speech cues are conveyed by the hearing aid or implant in order to optimize the fine tuning of the device and guide rehabilitation. Analytical tests bypass effects of language competency and are also language independent. Moreover, the perceptual difficulty of the test can be varied by presenting speech signals that are more (or less) acoustically similar. The present feasibility study showed that normal-hearing children with normal cognitive and language development from about $2 \frac{1}{2}$ years and older do have the cognitive ability to understand analytical tests, given a clear association between sound and figure in the onomatopoeia test or given the right response task with the LAST-pak.

\section{General conclusions}

The normalization of the Göttinger tests permits meaningful comparisons of normal-hearing and hearing-impaired child performance. However, tests must be administered with caution to children between $2 \frac{1}{2}$ and 3;0 years of age. Although the test words are within the vocabulary of the child, poor performance could result from auditory factors but also from sub-optimal listening strategies. Hearing-impaired children are often delayed in their development of speech and language skills and have even more restricted vocabularies than their normal-hearing peers. It is the responsibility of the experimenter to ensure that the test words are within the vocabulary of the child and to determine whether a low score results from auditory impairment or from cognitive inabilities. Future studies including hearingimpaired children will also focus on test-retest validity and reliability. Without this information it is difficult to determine whether changes in performance over time on a given test are meaningful.

In the near future the Göttinger tests will also be evaluated in noise with normal-hearing children in a multi-center study in Flanders. The spectrum of the speech-weighted noise corresponds to that of the speakers (Laneau et al., 2004).

Due to the relatively large gap between competence and performance very few tests are available for preschool children. Robbins and Kirk (1996) proposed a series of tests intended for profoundly hearing-impaired children between two and five years of age. In Screening Inventory of Perception Skills (SCIPS, Osberger et al., 1991) children discriminate between pairs of words differing in duration and stress, or in segmental cues. A single word is presented on each trial and the child is asked to respond if the presented stimulus matches the target words, and to do nothing if the stimulus and target words differ ("Go/No Go"). In the Grammatical Analysis of Elicited Language-Preschool Level (GAEL-P) test children are familiarized with 30 objects in the auditory-plus-visual modality. This test, developed by Moog et al. (1983), was modified by Robbins and Kirk into a closed-set measure of auditory-only word recognition. In the "Mr Potato Head Task" children were asked to carry out commands in assembling a Mr Potato Head toy (Robbins, 1994). Normative testing showed that some children under 3;0 years of age had difficulty with the "Go/No Go" response paradigm of the SCIPS, and performed better 
when providing a imitative response. Moreover, the open-set speech results (Mr Potato Head) were more varied than the closed-set ones. Finitzo-Hieber et al. (1980) investigated the use of familiar environmental sounds as an alternative to speech stimuli for assessing auditory discrimination abilities of children who are not capable of differentiating verbal stimuli. They developed the Sounds Effects Recognition Test (SERT), a standardized closed-set format with a picture-pointing response. The authors concluded that by the age of three a child should be able to identify an average of 25-30 environmental test sounds.

Although speech is more meaningful than isolated phonemes and therefore more likely to hold the attention of very young children, it is important to be able to determine speech feature discrimination, for instance when considering adjustments of the speech processor map(s) in a child with a cochlear implant. Analytical tests evaluate the auditory-only performance of children with a profound hearing loss, and they do not take vocabulary and/or language skills into account. An audiovisual speech feature test for 4-5 year olds (Tyler et al., 1991; Tyler, 1993) showed that voicing and nasality features were transmitted more effectively than frication, duration and place features in children wearing the Nucleus device (Tyler, 1991). The present study shows that very young normal-hearing children with normal cognitive and language development do not have the memory capabilities to indicate the odd one out in a $3 \mathrm{I} 2 \mathrm{AFC}$ test procedure, but that they can reliably point to the stimulus that the experimenter asks for. In a future study the test procedure of the LAST-pak will be modified to include a carrier sentence asking randomly for one of the speech stimuli under test after presenting the sequence of sounds. In addition, in order for the onomatopoeia test to be useful for evaluation of hearing-impaired children, the representation of several figures needs to be reconsidered.

Acquiring tests: The CD's and test materials of the Dutch Göttinger test lists and/or the LAST (-pak) can be obtained at the Lab. Exp. ORL. The software with which the LAST is presented is offered as a free service to the community for research or educational purposes.

\section{Acknowledgements}

We sincerely thank all the children who participated in the different studies described in this paper and our colleagues at the A.Z. St Jan in Brugge, the Lessius Hogeschool in Antwerp, and the Rehabilitation Center St Lievenspoort in Gent for their participation in this multi-center study. Special thanks to "Baby home", one of the day care centers of the K.U. Leuven for assistance in testing the youngest children. Finally, all students are acknowledged for diligently carrying out part of the practical work. Research was funded by the Fonds voor Wetenschappelijk Onderzoek-Vlaanderen (Belgium).

\section{References}

Beijnon, A.J., van Durme, M., Brokx, J.P.L., 1992. De Antwerpen-Nijmegen testbatterij: een verzameling auditieve tests voor ernstig slechthorenden. Unpublished documents.

Boets, B., Wouters, J., van Wieringen, A., Ghesquière, P., submitted for publication. Auditory temporal information processing in preschool children at risk of dyslexia: relations with phonological abilities and developing literacy skills. Brain Lang.

Bosman, A.J., Wouters, J., Damman, W., 1995. Realisatie van een cd voor spraakaudiometrie in Vlaanderen. Logopedie en Foniatrie 9, 218-225.

Chanet, T., 1998. De PAP-V: een gehoortestbatterij voor jonge ernstig slechthorenden kinderen: evaluatie naar betrouwbaarheid en validiteit. Master thesis, Logopedie en Audiologie, Katholieke Universiteit Leuven.

Crul, A.M., 1984. SAP: spraakaudiometrie met plaatjes. Logopedie Foniatrie 56, 31-35.

Dorman, M.F., Soli, S., Dankowski, K., Smith, L.M., McCandless, G., Parkin, J., 1990. Acoustic cues for consonant identification by patients who use the Ineraid cochlear implant. J. Acoust. Soc. Amer. 88, 2074-2079.

Finitzo-Hieber, T., Gerling, I.J., Matkin, N.D., CherowSkalka, E., 1980. A sound effects recognition test for the pediatric audiological evaluation. Ear Hear. 1 (5), 271-276.

Gommers, K., 1998. De PAP-V: een gehoortestbatterij voor ernstig slechthorende en cochleaire implant kinderen. Master thesis, Logopedie en Audiologie, Katholieke Universiteit Leuven. 
Goossens, K., 2004. Haalbaarheid van Göttinger I test, identificatie van eenvoudige woorden test en onomatopeeëntests bij kinderen tussen 2 en 3 jaar. Master thesis, Logopedie en Audiologie, Katholieke Universiteit Leuven.

Huysmans, I., 1997. Normering van woordenlijsten voor spraakaudiometrie bij kinderen. Master thesis, Logopedie en Audiologie, Katholieke Universiteit Leuven.

Kirk, K.I., Diefendorf, A.O., Pisoni, D.B., Robbins, A.M., 1997. Assessing speech perception in children. In: Mendel, L.L., Danhauer, J.L. (Eds.), Audiologic Evaluation and Management and Speech Perception Assessment. Singular Publishing, pp. 101-132.

Lambrechts, M., 1979. De Göttinger spraakverstaanbaarheidstest II: Aanpassing van een Duitse spraakaudiometrische test voor vijf- en zesjarigen aan het Nederlands. Thesis Hogeschool Brugge.

Laneau, J., van Wieringen, A., Wouters, J., 2004. Vlaamse opname van Woordenlijsten voor spraakaudiometrie: spraakverstaan in ruis bij kinderen. Een hercompilatie van bestaand materiaal.

Laneau, J., Boets, B., Moonen, M., van Wieringen, A., Wouters, J., 2005. A flexible auditory research platform using acoustic or electric stimuli for adults and young children. J. Neurosci. Meth. 142, 131-136.

Lemkens, 2000. Identificatie van het aantal lettergrepen, identificatie van de Göttingerwoorden en identificatie van eenvoudige zinnen bij cochleair implant- en gehoorgestoorde kinderen. Master thesis Logopedie en Audiologie, Katholieke Universiteit Leuven.

Moog, J.S., Kozak, V.J., Geers, A.E., 1983. Grammatical Analysis of Elicited Language-Pre-sentence Level. Central Institute of the Deaf, St Louis, MO.

Osberger, M.J., Miyamoto, R.T., Zimmerman-Phillips, S., Kemink, J.L., Stroer, B.S., Firszt, J.B., Novak, M.A., 1991. Independent evaluation of the speech perception abilities of children with the Nucleus 22-channel cochlear implant system. Ear Hear. 12 (Suppl.), 105-115.

Plasmans, A., 1999. Ontwikkeling van een analytische identificatietest met betekenisvolle woorden voor zeer jonge kinderen met een cochleair implantaat of hoorapparaat. Master thesis Logopedie en Audiologie, Katholieke Universiteit Leuven.

Robbins, A.M., 1994. Mr Potato Head Task. Indiana University School of Medicine, Indianapolis, IN.

Robbins, A.M., Kirk, K.I., 1996. Speech perception assessment and performance in pediatric cochlear implant users. Semin. Hear. 17, 353-369.

Spencer, L.J., Tye-Murray, N., Tomblin, J.B., 1998. The production of English inflectional morphology, speech production and listening performance in children with cochlear implants. Ear Hear. 19, 310-318.
Spencer, L.J., Barker, B.A., Tomblin, J.B., 2003. Exploring the language and literacy outcomes of pediatric cochlear implant users. Ear Hear. 24, 236-247.

SPSS 12.0, 2004. SPSS Inc., Chicago, IL.

Svirsky, M.A., Teoh, S.-W., Neuburger, H., 2004. Development of language and speech perception in congenitally, profoundly deaf children as a function of age at cochlear implantation. Audiol Neurootol 9, 224-233.

Tyler, R.S., 1991. What can we learn about hearing aids from cochlear implants? Ear Hear. 12 (suppl 6), 177S-186S.

Tyler, R.S., 1993. Speech perception by children. In: Tyler, R.S. (Ed.), Cochlear Implants: Audiological Foundations. pp. 191-256.

Tyler, R.S., Moore, B.C.J., 1992. Consonant recognition by some of the better cochlear implant patients. J. Acoust. Soc. Amer. 92, 3068-3077.

Tyler, R.S., Fryauf-Bertschy, H., Kelsay, D., 1991. Audiovisual Feature Test for Young Children. University of Iowa, Iowa City.

van Gompel, J., Vanhulle, R., 1979. Spraakaudiometrie bij kinderen: aanpassing van de Göttinger Sprackverständnistest I aan het Nederlands. Tijdschrift Logopedie Audiologie 9, 1-12.

van Hal, E., 2000. Onomatopeeën en identificatie van eenvoudige woorden bij jonge slechthorende en CI-kinderen. Master thesis, Logopedie en Audiologie, Katholieke Universiteit Leuven.

van Kerschaver, E., Stappaert, L., 2002. De ALGO gehoorscreening, rapport van werkjaar 2000. Kind en Gezin Brussel.

van Wieringen, A., Wouters, J., 1999. Natural vowel and consonant recognition by Laura cochlear implantees. Ear Hear. 20, 89-103.

van Wieringen, A., Wouters, J., 2000. Assessing progress in speech perception with the LAURA cochlear implant device. In: Waltzman, S.B., Cohen, N.L. (Eds.), Cochlear Implants. Thieme Medical Publishers Inc., pp. 355-356.

van Wieringen, Daemers, K., Desloovere, M., 1998. Handleiding PAP-V. Unpublished document.

Vanrie, L., 2004. Auditieve temporele signaalverwerking bij jonge kinderen. Master thesis Logopedie en Audiologie, Katholieke Universiteit Leuven.

Wouters, J., Damman, W., Bosman, A.J., 1994a. Vlaamse opname van woordenlijsten voor spraakaudiometrie. Compact Disc DDD, S1694006.

Wouters, J., Damman, W., Bosman, A.J., 1994b. Vlaamse opname voor woordenlijsten voor Spraakaudiometrie. Logopedie 6, 28-33.

Yoshinaga-Itano, C., Sedey, A.L., Coulter, D.K., Mehl, A.L., 1998. Language of early- and later identified children with hearing loss. Pediatrics 102 (5), 1161-1171. 